\title{
Diarrhoea and Intestinal Microbiota
}

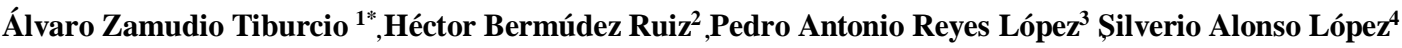

${ }^{1}$ Gastroenterology Department. Intestinal Microbiota Transplantation Unit. Pennsylvania 209, corner Kansas. Naples colony. ZIP 03820. City Hall Benito Juárez. Office \# 12. (Naples Medical Specialties). Mexico City Mexico.

${ }^{2}$ Endoscopy Service. Oncology Hospital. National Medical Center. XXI century. Mexican Social Security Institute.

${ }^{3}$ Research Department. National Institute of Cardiology "Ignacio Chávez".

${ }^{4}$ Urologist. Naples Medical Specialties

*Corresponding author: Álvaro Zamudio Tiburcio, Gastroenterology Department. Intestinal Microbiota Transplantation Unit. Pennsylvania 209, corner Kansas. Naples colony. ZIP 03820. City Hall Benito Juárez. Office \# 12. (Naples Medical Specialties). Mexico City Mexico.

Received Date: June 11, 2020; Accepted Date: June 23, 2020; Published Date: June 26, 2020.

Citation: Álvaro Z Tiburcio, Héctor B Ruiz, Reyes López P A, Silverio A López, (2020) Diarrhoea And Intestinal Microbiota. Journal of Clinical Case Reports and Studies, 1(2): Doi: 10.31579/2690-8808/006

Copyright: ( ) 2020. Álvaro Zamudio Tiburcio. This is an open-access article distributed under the terms of the Creative Commons Attribution License, which permits unrestricted use, distribution, and reproduction in any medium, provided the original author and source are credited.

\begin{abstract}
We carry out a review of the world literature, regarding the role played by the Intestinal Microbiota (IM), -when transplantedin the decrease and disappearance of diarrhoea, in many conditions. Some acute and most chronic.

Also, we show our little experience regarding the effect of Intestinal Microbiota Transplant (IMT), also known as Fecal Microbiota Transplant (FMT).

We refer how patients with Irritable Bowel Syndrome, Diarrhoea variety, Anxiety, Systemic Lupus Erythematosus, Pseudomembranous Colitis, Intestinal Malabsorption Syndrome, Amyotrophic Lateral Sclerosis and Retroperitoneal Cancer operated on 4 occasions, secondary to left seminoma and right testicular teratoma (excised).

We show that in all of them, the diarrhoea was reduced substantially and that the complications that appeared were minimal; without relevance or significant effect.
\end{abstract}

Key Words: chronic diarrhoea; fecal microbiota transplantation (FMT); intestinal microbiota transplantation (IMT); Intestinal microbiota (IM)

\section{Introduction:}

We carry out a review of the world literature, regarding the role played by the Intestinal Microbiota (IM), -when transplanted-in the decrease and disappearance of diarrhoea, in many conditions. Some acute and most chronic.

Also, we show our little experience regarding the effect of Intestinal Microbiota Transplant (IMT), also known as Fecal Microbiota Transplant (FMT).

We refer how patients with Irritable Bowel Syndrome, Diarrhoea variety,
Anxiety, Systemic Lupus Erythematosus, Pseudomembranous Colitis, Intestinal Malabsorption Syndrome, Amyotrophic Lateral Sclerosis and Retroperitoneal Cancer operated on 4 occasions, secondary to left seminoma and right testicular teratoma (excised).

We show that in all of them, the diarrhoea was reduced substantially and that the complications that appeared were minimal; without relevance or significant effect

Findings. We analyze 17 cases with 33 to 86 years of age. 9 male and 8 female. The main diagnosis appears in the next table.

\begin{tabular}{|c|l|}
\hline Main Diagnostic & \\
\hline Anxiety. & 7 cases \\
\hline Ibs, variety diarrhoea & 4 cases \\
\hline $\begin{array}{c}\text { Retroperitoneal cancer operated in } 4 \\
\text { Occasions, secondary to seminoma } \\
\text { Left and right teratoma }\end{array}$ & 4 cases \\
\hline Amyotrophic lateral sclerosis \\
Active systemic lupus erythematosous \\
Bad absorption syndrome \\
Pseudomembranous enterocolitis \\
Chronic alcoholism & 2 cases \\
Total & \\
\hline
\end{tabular}

Table 1: The evolution time of the stools appears in the next Table. 


\begin{tabular}{|c|c|}
\hline 5 Days & 1 patient \\
\hline 1 Month & 1 patient \\
\hline 2 Months & 3 patients (alternate days) \\
\hline 3 Months & 4 patients (alternate days) \\
\hline 5 Months & 1 patient (alternate days) \\
\hline 6 Months & 1 patients (alternate days) \\
\hline 12 Months & 1 patient (alternate days) \\
\hline 24 Months & 1 patient (alternate days \\
\hline 15 Months & 1 patient (alternate days \\
\hline 3 Years & 1 patient (alternate days \\
\hline 5 Years & $\mathbf{1 7}$ Cases \\
\hline Total & \\
\hline
\end{tabular}

Table 2:Time of Evolution of Depositions

Number of Depositions, Daily. They happened in number from 2, to 8 , in 24 hours. The number of evacuations that was presented the most was 6 a day. Some of the evacuations were on alternate days. In 3 cases there were bloody stools and these occurred in a patient with pseudomembranous enterocolitis, in a patient with rectal polyps and in rectal vascular ectasia.

In addition, other secondary comorbidities appeared, such as the following table (Evolutions is included).

\begin{tabular}{|c|c|}
\hline 1. & Anxiety. 7 cases (Separate comment) \\
\hline 2. & Obesity. 6 cases ( 3 patients started losing weight) \\
\hline 3. & IBS, diarrhoea variety. 6 cases (Separate comment) \\
\hline 4. & Diverticular disease of the colon. 5 cases (Pending long-term evaluation) \\
\hline 5. & Arterial hypertension. 5 cases (Without improvement) \\
\hline 6. & Hiatal hernia. 4 cases (3 patients improved completely) \\
\hline 7. & Diabetes mellitus type 2, stable adult. 3 cases (Without improvement) \\
\hline 8. & Benign prostatic hypertrophy. 3 cases (Without improvement) \\
\hline 9. & Neuropathies. 3 cases (He improved the pain) \\
\hline 10. & Dyslipidemia. 3 cases (Pending long-term evaluation) \\
\hline 11. & Lactose intolerance. 2 cases (They improved in 10 days) \\
\hline 12. & $\begin{array}{l}\text { Dermatopathy. } 2 \text { cases (They were completely corrected before two } \\
14 \text { weeks) }\end{array}$ \\
\hline 13. & Spastic colon. 2 cases (They were totally corrected, in 8 days) \\
\hline 14 & $\begin{array}{l}\text { Peripheral vascular insufficiency in podic members. } 2 \text { cases (Without } \\
\text { 17improvement) }\end{array}$ \\
\hline 15 & Allergy to cold. 2 cases (They gave in 1 week) \\
\hline 16 & Disc degeneration and listesis grade I-II (L-2) (Decreased pain, at 10 18days) \\
\hline 17 & Malnutrition. (Corrected in 4 months) \\
\hline 18 & COPD. (Without improvement) \\
\hline 19 & Fibromyalgia. (It improved completely a week). \\
\hline 20 & Lupus glomerulonephritis. (Biopsy was required to Evaluate the case) \\
\hline 21 & Non-alcoholic fatty liver. (In Ultrasound control under 1 to 0 ). \\
\hline 22 & Uterine myomatosis. (Without improvement) \\
\hline 23 & Facial neuralgia on the left side. (It improved completely in 10 days) \\
\hline 24 & Weightloss. (At 48 hours he no longer lost weight) \\
\hline 25 & Insufficient weight. (He gained 4 Pounds in 10 days). \\
\hline 26 & Bilateral pterygium, predominantly left. (Without improvement) \\
\hline 27 & Neurocardiogenic syndrome. (Without improvement) \\
\hline 28 & Smoking. (Without improvement) \\
\hline 29 & Vulvovaginitis. (Decreased, by 8 days) \\
\hline
\end{tabular}

\section{Table 3: Secondary Comorbidities}

Type of Transplant. He was colonic in 13 cases, Jejunal in 3 and mixed (jejunal and colonic in 3). The patient with psudomembranous enterocolitis required 3 transplants.

The Findings of the Endoscopic Studies Were: 


\begin{tabular}{|l|l|}
\hline 1 & Colon diverticular disease. Three cases. \\
\hline 2 & Gastritis. One case \\
\hline 3 & gastric polyp. One case (remove) \\
\hline 4 & rectorragy for rectal vascular ectasia (spontaneously yielded) \\
\hline 5 & rectorragy for rectal polyps. (yielded) \\
\hline
\end{tabular}

Table 4: Endoscopic Findings

The Amount of Transplanted Microbiota was $200 \mathrm{ml}$. In ascending colon, $100 \mathrm{ml}$. In transverse colon and $200 \mathrm{ml}$. In descending colon in 10 patients. In the patient with pseudomembranous Colitis, 3 transplants were performed, for the same amount, on alternate days.

In 2 cases $250 \mathrm{ml}$ were instilled into the jejunum. And then in ascending colon $200 \mathrm{ml} .100 \mathrm{ml}$. In transverse colon and $200 \mathrm{ml}$. In the descending colon. In 1 case: $250 \mathrm{ml}$. In the jejunum And then: $100 \mathrm{ml}$. In ascending colon, $50 \mathrm{ml}$. In transverse colon and $100 \mathrm{ml}$. In descending colon.

We applied the Microbiota in 3 cases, through the jejunum, depositing $250 \mathrm{ml}$ in one case. And in another $400 \mathrm{ml}$.

Complications. They were presented in 4 cases. One of them diarrhoea in number of 8 a day and abdominal pain. They ceded at 24 hours spontaneously. The second with diarrhoea and abdominal pain, which yielded with antispasmodics and probiotics at 48 hours. The third with bloating and pain on both flanks, which disappeared at 24 hours. The fourth case presented with diarrhoea, from overeating chile, mole and tamarind. Containing the problem with antispasmodics, probiotics and antidiarrheals. We consider that this case was not a complication of the IMT, but of the excess when eating, despite having been told otherwise. The problem gave way in 3 days.

Although comments have already been made on some comorbidities, the time and percentages of the improvements appear below. Which occurred in all cases.

In the Main Diagnosis, the Evolution Was:Anxiety 13 Cases. (Decreased from the 4th Day to 3 weeks, in all cases, considering the Hamilton Scale).

The patient with the greatest anxiety had 40 points, and the one with the least anxiety 16 . In the comparative lines, the initial anxiety and below the anxiety after the IMT are observed:

Initial Anxiety: $\quad 20,40,37,24,21,22,33,22,32,16,19,30,22$.

Anxiety with IMT: 10, 04, 06, 09, 12, 13, 08, 09, 16, 04, 05, 14, 08.

Case number 9 was the survey conducted in its first phase to the son of the lady, because she is unconscious.

The 13 patients with IBS, Variety diarrhoea, as initial diagnosis, as well as the 4 patients with the same Syndrome detected as secondary comorbidity, no longer had liquid stools, at 2 weeks after the IMT.

The 2 patients with lactose intolerance and the patient with retroperitoneal cancer operated on 4 occasions, secondary to left seminoma and right teratoma (extirpated) tolerate all foods and beverages, including mole, chile, guacamole and beer. Patients with IBS, variety diarrhoea, comment that their stools are formed. (In The long-term cases, he say that for years did not evacuate formed and solid)

\section{Literature Review.}

One of the conditions that are most often treated with IMT is diarrhoea. All over the world, the criteria tend to be standardized and the methodology to equalize, in order to obtain better answers [1, 2, 3].

According to the World Health Organization Diarrhoea is the passage of 3 or more loose or liquid stools per day, or more frequently than is normal for the individual [4].

Although in our casuistry we do not address patients with diarrhoea, such as those caused by bacteria, parasites or contaminated water, but those that occur in processes resulting from mainly gastrointestinal conditions, predominantly Irritable Bowel Syndrome, secondary to alterations in the intestinal microbiota (IM).

Diarrhoea, caused by IBS, inflammatory processes (IBD, Crohn's disease, immunological disorders, and others), are frequent and can be seen to affect the quality of life and good personal development $[5,6,7]$.

The referenced authors have witnessed the importance of Intestinal Microbiota Transplantation in diseases as frequent as IBS, diarrhoea variety [8], and the inflammatory processes of Ulcerative Colitis and Crohn's Disease, with generation of diarrheic evacuations [9, 10, 11, 12], as well as the correction, with an enormous frequency of inflammatory processes and consequently diarrhoea $[13,14]$.

Remission of diarrheal processes has been frequently observed in other diagnoses, such as Lupus erythematosous [15].

The most abundant cases in the world literature are $C$. difficile diarrhoea, which we include only one case; our casuistry included 17 patients.

Various information reveals that Fecal Microbiota Transplantation treats them satisfactorily from 80 to $90 \%$ [16]. We do not include $C$. difficile recurrent diarrhoea [17, 18, 19]. For having been successfully addressed.

Now, regarding our cases, we consider that one of the reasons for the decrease in diarrhoea was the tireless search for excellent donors, to whom we not only performed a deep medical history [20], but also carried out the studies required [21]. And above all, we use the criterion of having donors under the age of 30 years [22].

At present, it is necessary not forget the recommendations of the U. S. FDA [23], which indicate that from March 23, 2020 we must carry out:

- Questions aimed at identifying donors who may be infected with SARSCoV-2.

- Donor and / or donor stool test for SARS-CoV-2.

- Development of criteria for the exclusion of donors and donor feces based on detection and tests. 
- Informed consent that includes information on the potential for transmission of SARS-CoV-2 through FMT, including FMT prepared from donor faeces that are asymptomatic for COVID-19.

These statements are reinforced by the FDA on April 9, 2020 [24].

We add that those samples processed before November 1, 2019, may be useful, if the processing was based on all the rules inherent to Fecal Microbiota Transplantation [25].

\section{Comments.}

In our casuistry we observed that the majority of patients with chronic diarrhoea had anxiety, as the first diagnosis, followed by IBS, diarrhoea variety. And in all of them there were good results. We note that both primary and secondary comorbidities improved in most patients. Most of the transplants performed were performed in the colon, with amounts around $500 \mathrm{ml}$. Of microbiota.

We have started to administer IMT in cancer, with surprising results. We tried that the patient was in a remission phase and the fact that the fall of the weight stops, as well as recover the appetite, especially of foods that he liked, for us was a truly favorable surprise.

The comments made by some patients with chronic diarrhoea, which included that they did not evacuate solid or formed for months, also surprised us, as well as the recovery of weight and the decrease of intestinal disorders added.

Something that we cannot forget in the Fecal Microbiota Transplant methodology is Dysbiosis, a process that is present in all cases and whether it is called dysbiosis, intestinal dysbiosis or dysbacteriosis [26], and that occurs when the normal balance is altered of the normal flow of the microbiota, generates specific symptoms and has prevention, which we can try [27]. This inflammatory process is the result of an inadequate diet, the use of antibiotics, exaggerated intake of alcohol, stress or certain drugs. It can be reversed, or at the hands try with changes in habits [28, 29].

\section{Conclusions}

- Mixed Intestinal Microbiota Transplant (jejunum and colon, gives better results).

- The increase of the amount of $500 \mathrm{ml}$. It helps to improve the morbid processes, more quickly.

- Complications are usually benign and correct alone or with conventional treatment.

- We believe that it is time to gradually add more conditions to the list of cases

treatable with IMT.

- The IMT should be added to the therapeutic guidelines. In the world.

Given the presence of COVID-19, the U. S. FDA recommends only using microbiota made before November 1, 2019, and searching for donors for SARS-CoV-2 [30, 31].

Conflicts of interest: The authors declare that they do NOT have affiliation or participation in organizations with financial interests.
Ethical approval: The present report does not contain any study with human or animal subjects made by the authors.

Informed consent: The authors obtained written informed consent from the patient in order to develop this report.

\section{References}

1. Carroll IM, Ringel-Kulka T, Keku TO, Chang YH, Packey CD, et al. (2011). Molecular analysis of the luminal- and mucosalassociated intestinal microbiota in diarrhea-predominant irritable bowel syndrome. Am J Physiol Gastrointest Liver Physiol, 301. (5): G799-807.

2. Sohn W, Lee OY, Lee SP, Lee KN, Jun DW, Lee HL, et al. (2014). Mast cell number, substance $P$ and vasoactive intestinal peptide in irritable bowel syndrome with diarrhea. Scand J Gastroenterol, 49: 43•51.

3. Polanco Allué I. (2015). Microbiota y enfermedades gastrointestinales. Anales de Pediatría. Dic, 83. (6): 365-452.

4. Zanella Terrier MC, Simonet ML, Bichard P, Frossard JL. (2014). Recurrent Clostridium difficile infections: the importance of the intestinal microbiota. World J Gastroenterol. 20: 7416-7423.

5. Garrett WS, Gallini CA, Yatsunenko T, Michaud M, DuBois A, et al. (2010). Enterobacteriaceae act in concert with the gut microbiota to induce spontaneous and maternally transmitted colitis. Cell Host Microbe. (8): 3: 292-300.

6. Bennet JD, Brinkman M. (1989). Treatment of ulcerative colitis by implantation of normal colonic flora. Lancet. 1. (8630): 164.

7. Park JH, Rhee PL, Kim G, Lee JH, Kim YH, et al. (2006). Enteroendocrine cell counts correlate with visceral hypersensitivity in patients with diarrhoea-predominant irritable bowel syndrome. Neurogastroenterol Motil. 18. (7): 539-46.

8. Moayyedi P, Surette MG, Kim PT, Libertucci J, Wolfe M, et al. (2015). Fecal microbiota transplantation induces remission in patients with active ulcerative colitis in a randomized controlled trial. Gastroenterology. 149. (1): 102-109.e6.

9. Kunde S, Pham A, Bonczyk S, Crumb T, Duba M, et al. (2013). Safety, tolerability, and clinical response after fecal Transplantation in children and young adults with ulcerative colitis. J Pediatr Gastroenterol Nutr. 56. (6): 597-601.

10. Borody T, Wettstein A, Campbell J, Leis S, Torres M, et al. (2012). Fecal microbiota transplantation in ulcerative colitis: Review of 24 years experience. Am J Gastroenterol. Conf 77th Annu Sci Meet Am Coll Gastroenterol. 107: S665.

11. Rossen NG, MacDonald JK, de Vries EM, D`Haens GR, de Vos WM, et al. (2015). Fecal microbiota transplantation as novel therapy in gastroenterology: A systematic review. World J Gastroenterol. 21. (17): 5359-5371.

12. Hohmann EL, Ananthakrishnan AN, Deshpande V. (2014). Case Records of The Massachusetts General Hospital. Case 25-2014. A 37-year-old Man with ulcerative colitis and bloody diarrhea. N Engl J Med. 371: 668-675.

13. Vermeire S, Joossens M, Verbeke K, Wag J, Machiels K, et al. (2016). Donor Species Richness Determines Faecal Microbiota Transplantation Success in Inflammatory Bowel Disease. J Crohns Colitis. 10. (4): 387-94.

14. Suskind DL, Brittnacher MJ, Wahbeh G, Shaffer ML, Hayden HS, et al. (2015). Fecal microbial transplant effect on clinical outcomes and Fecal microbiome in active Crohn's disease. Inflamm Bowel Dis. (3): 556-63.

15. Gianotti RJ, Moss AC. et al. (2017). Fecal Microbiota Transplantation: From Clostridium difficile to Inflammatory Bowel Disease. Gastroenterol Hepatotol (N Y). 13. (4): 209-213. 
16. Lynch SM, Mu J, Grady JJ, Stevens RG, Devers TJ, et al. (2019). Fecal Microbiota Transplantation for Clostridium Difficile Infection: A One-Center Experience. Dig Dis. 37. (6): 467-472.

17. Rao K, Young VB. (2015). Fecal Microbiota Transplantation for the Management of Clostridium difficile Infection. Infect Dis Clin North Am. 29. (1): 109-122.

18. Gravito-Soares M, Gravito-Soares E, Portela F, Ferrerira M, Sofia C, et al. (2017). Fecal microbiota transplantation in recurrent Clostridium difficile Infection in a patient with concomitant inflammatory bowel disease. Rev. Esp. Enferm. Dig. 109. (6): 473-476.

19. Wilson BC, Vatanen T, Cutfield WS, O’Sullivan JM, et al. (2019). The Super- Donor Phenomenon in Fecal Microbiota Transplantation. Front Cell Infect Microbiol. 9: 2.

20. Fisher M. (2019). Recent Research on Fecal Microbiota Transplantation in Inflammatory Bowel Disease Patients. Gastroenterol Hepatol (N Y). 15. (1): 44-47.

21. Woodworth MH, Carpentieri C, Sitchenko KL, Kraft CS, et al. (2017). Challenges in Fecal donor selection and screening for fecal microbiota Transplantation: A review. Gut Microbes. 8. (3): 225-237.

22. Fecal Microbiota for Transplantation: Safety Alert - Regarding Additional Safety Protections Pertaining to SARS-CoV-2 and COVID-19. FDA: 03/23/2020.
23. Information Pertaining to Additional Safety Protections Regarding Use of Fecal Microbiota for Transplantation Screening Donors For COVID-19 and Exposure to SARS-CoV2 and Testing for SARS-CoV-2. FDA: April 9, 2020.

24. Álvaro Zamudio Tiburcio and Silverio Alonso López. (2020). Is Dysbiosis the Source of the Problem in SARS-CoV-2 Infection? EC Microbiology Special Issue. SI.02 (2020): 20-22

25. Hawrelak JA, Myers SP. (2004). The Causes of Intestinal Dysbiosis: A Review. Altern Med Rev. (2): 180-197.

26. Denton CP, Murray C. (2019). Cause or effect? Interpreting emerging evidence for dysbiosis in systemic sclerosis. Arthritis Research \& Therapy $21,81$.

27. Belizário JE, Faintuch J. (2018). Microbiome and Gut Dysbiosis. Exp Suppl. 109: 459-476.

28. Hevia A, Milani C, López P, Cuervo A, Arboleya S, et al. (2014). Intestinal dysbiosis associated with Systemic Lupus Erythematosus. mBio. 5. (5): e01548-14.

29. FDA Issues Alert on Potential Risk of SARS-CoV-2 Transmission Trought FMT. Contagion Live. Infectious Diseases Today. 2020 March 24.

30. Fecal Microbiota for Transplantation: New Safety Information Regarding Additional Protections for Screening Donors for COVID-19 And Exposure to SARS-CoV-2 and Testing for SARS-CoV-2. U.S.FOOD \& DRUG. 4/09/2020. 